\title{
Análise de Burnout em profissionais de uma unidade de emergência de um hospital geral ${ }^{1}$
}

\section{Burnout analyses about professionals of an emergency unit of a general hospital}

\section{Análisis de Burnout en profesionales de una unidad de emergencia de un hospital general}

\author{
Renata Schwanke Ritter', Eniva Miladi Fernandes Stumm"', Rosane Maria Kircher ${ }^{\prime \prime \prime}$
}

\begin{abstract}
${ }_{1}^{1}$ Artigo original construído a partir dos resultados de um Trabalho de Conclusão de Curso (TCC), Graduação em Enfermagem da Universidade Regional do Noroeste do Estado do Rio Grande do Sul (UNIJUí), de autoria de Renata Schwanke Ritter, orientado pela docente Eniva M. F. Stumm. O mesmo foi defendido em 04/12/2007.

I Enfermeira, egressa do Curso de Enfermagem da UNIJUÍ. Enfermeira da Clínica Médica do Hospital Ivan Goulart- São Borja/RS. Pósgraduanda em Enfermagem Cardiológica pelo Instituto São Camilo/POA. Email: renata.ritter87@yahoo.com.br.

"Enfermeira, Mestre em Administração - Recursos Humanos, pela Universidade Federal do Rio Grande do Sul (UFRGS). Docente da UNIJUí. Email: eniva@unijui.edu.br.

III Doutora em Engenharia Elétrica - Métodos de Apoio à Decisão. Professora de Estatística do Centro de Ciências Rurais de São Gabriel da Universidade Federal do Pampa (CRSG/UNIPAMPA). Email: rosanek@smail.ufsm.br.
\end{abstract}

\section{RESUMO}

A Unidade de Emergência é um ambiente no qual situações de ansiedade, pressão e estresse, são comuns. A pesquisa objetiva analisar as variáveis da Síndrome de Burnout em profissionais de enfermagem e médicos que atuam na Unidade de Emergência de um hospital geral. É descritiva, quantitativa, desenvolvida em um hospital do noroeste/RS, em 2007, com 38 profissionais. Os instrumentos de coleta de dados foram MBI e dados sociodemográficos. Para o tratamento estatístico utilizou-se SPSS e estatística descritiva. O perfil é 57,9\% feminino, 25-30 anos de idade, 60,5\% casado e com filhos, 70,3\% ensino médio, 2,7\% graduação e 27,0\% especialização. 34,2\% atuam há 3,5 anos na profissão, 55,3\% 3,5 anos na Emergência e 56,8\% dedicam-se exclusivamente ao trabalho neste local. Quanto às dimensões da síndrome, escores baixos para Desgaste Emocional e Despersonalização e alto para Incompetência (escore reverso). Na equipe médica as médias de Desgaste Emocional e Despersonalização são maiores do que na de enfermagem e a Incompetência, similaridade em ambas. Variáveis relacionadas ao Contexto do Trabalho apresentaram escores elevados nas duas categorias, a equipe médica obteve médias mais altas. A produção de maior conhecimento sobre a temática pode contribuir no cotidiano destes profissionais e instigar pesquisadores à continuidade de estudos.

Descritores: Serviços Médicos de Emergência; Burnout Profissional; Pessoal de Saúde.

\section{ABSTRACT}

The emergency unit is an environment where unseeded, pressure and stress situation are usual. The research analyses the Burnout Syndrome variables of on nurse and physician professionals of an emergency unit of a general hospital. It is descriptive and quantitative, developed in a hospital in northwest/RS, in 2007, with 38 professionals. The data were collected through the Maslash Burnout Inventory and socio-demographic data. For the statistics treatment were used SPSS and descriptive statistics. The population profile is $57,9 \%$ female, between 25 and 30 years old, $60,5 \%$ married and they have children, $70,3 \%$ have finished high school,2,7\% are graduated and $27 \%$ are specialized. $34,2 \%$ of the professionals work in this area around 3,5 years, 55,3\% are around 3,5 years at the emergency unit and 56,8\% work exclusively at this place. About the Syndrome dimensions, low scores were verified for emotional decrease and depersonalization, and high incompetence (reverse score). The medical team presented averages of emotional decrease and depersonalization higher than the nursing's and the reverse score, similar in both. The variables related to the work context presented high scores in two categories, however, the medical team got higher averages. The production of the highest knowledge about the issue may contribute on the everyday of these professionals and to abet researchers, helping further studies.

Descriptors: Emergency Medical Services; Burnout, Professional; Health Personnel.

\section{RESUMEN}

La Unidad de Emergencia, ambiente en el cual situaciones de ansiedad, presión y stress, son comunes. La pesquisa analiza las variables de la Síndrome de Burnout en profesionales de enfermería y médicos que actúan en Unidad de emergencia de un hospital general. Es narrativa, cuantitativa, desarrollada en un hospital del Noroeste de RGS, en 2007, con 38 profesionales. Los instrumentos de colecta de datos fueron $\mathrm{MBI}$ y datos sociodemográficos. Para el tratamiento estadístico utilizando SPSS y estadística narrativa. El perfil es 57,9\% femenino, 25-30 años de edad, 60,5\% casado y con hijos, 70,30\% enseñanza media, 2,7\% graduación y 27\% especialización. 34,2\% actúan hace 3,5 años en la profesión, 55,3\% 3,5\% en Emergencias y $56,8 \%$ dedicándose exclusivamente al trabajo en este local. Cuanto al tamaño de la síndrome resultados bajos para el Desgaste Emocional y Despersonalización y alto para Incompetencia (resultado reverso). El equipo medico sufre mayor Desgaste Emocional y Despersonalización de que en enfermería y la Incompetencia similar en ambas. Relacionadas al Contexto del Trabajo ambas con resultados elevados. El equipo médico obtuvo media más altas. El mayor conocimiento sobre el tema podrá contribuir en el cotidiano de estos profesionales y estimular investigaciones de dichos estudios.

Descriptores: Servicios Médicos de Urgencia; Agotamiento Profesional; Personal de Salud. 


\section{NTRODUÇÃO}

O mundo do trabalho está cada vez mais complexo e, neste contexto, manter o bem-estar físico, psicológico e social está se tornando uma tarefa difícil, ciente de que manter a vida, enquanto se luta para ganhar a vida, nem sempre é fácil. "O desgaste a que as pessoas são submetidas, nos ambientes e nas relações com o trabalho, é um dos fatores na determinação das doenças dos mais significativos"(1).

Ao se reportar ao cotidiano dos profissionais da saúde em uma Unidade de Emergência, o mesmo é permeado de situações que envolvem conflitos, tensões, passíveis de gerarem estresse. Deles é exigido conhecimento técnico, científico, habilidades e competências que, muitas vezes, vão além de suas próprias formações. Uma equipe que atua em Emergência se depara com inúmeras situações, podendo estas serem desencadeadoras tanto de satisfação, quanto de frustração, sofrimento, impotência, dentre outros. Neste sentido, diversos autores $^{(2-5)}$ direcionaram seus estudos para a análise e compreensão do significado do sofrimento humano relacionado ao trabalho, especialmente a Síndrome de Burnout.

O termo Burnout funciona como metáfora para explicar que se chegou ao limite de esforço e, devido à falta de energia, não há mais condições físicas e mentais para trabalhar. Constitui-se em um quadro bem definido, uma síndrome tridimensional, caracterizada por: Exaustão Emocional, Despersonalização e Incompetência (sensação de realização pessoal e profissional reduzida). A referida síndrome aparece em profissionais que trabalham com pessoas, porque o tipo de relacionamento requer resposta emocional contínua ${ }^{(2,6)}$.

As principais causas de Burnout em profissionais da saúde incluem o contato contínuo com o sofrimento, a dor e a morte, a diminuição do valor social do profissional pela sua família, a sobrecarga de trabalho, a carência de recursos para desempenhar o papel adequadamente, a diminuição nos diversos tipos de recompensa e estímulos em sua atividade, a inquietação e ameaça de sofrer críticas por mau desempenho de sua prática laboral e dificuldades para encarar problemas éticos resultantes do avanço tecnológico ${ }^{(6)}$.

$O$ alvo preferencial do Burnout tende a ser os trabalhadores motivados, que se entregam totalmente ao trabalho como reação ao estresse laboral e acabam por entrar em colapso. Eles investem muito mais energia do que recebem em termos de reconhecimento e resultados. Os profissionais do setor de emergência são submetidos constantemente a sobrecargas de trabalho mentais, psíquicas e físicas, além da pressão para tomada de decisões rápidas, fundamentais no atendimento de emergência. Ainda, as jornadas de trabalho são extenuantes, dado o volume de usuários e a reposição de energia desses trabalhadores nem sempre é adequada ${ }^{(6)}$. São submetidos a plantões que, especialmente os noturnos, alteram seus biorritmos de sono, alimentação e atividades sociais. Além disso, ainda se dedicam a mais de um emprego, visto que os salários são baixos no setor e o ritmo de trabalho na emergência não os deixa impunes.

Nos últimos anos, pesquisas têm mostrado a importância da distribuição mundial do Burnout entre médicos e enfermeiras, com altos índices de exaustão emocional, baixa realização profissional e despersonalização, sendo constatados principalmente entre trabalhadores da saúde que atuam em unidades de emergência ${ }^{(3)}$

O cuidado permeia o fazer dos profissionais da saúde, e ao mesmo tempo, pode ser causador de danos à saúde do cuidador. Daí a importância desses trabalhadores aprenderem a cuidar de si, evitando e/ou reduzindo os danos desta ocupação e, consequentemente, preservando a saúde, com condições plenas de proporcionar uma assistência adequada aos usuários.

$O$ presente artigo tem como objetivo analisar as variáveis da Síndrome de Burnout em profissionais de enfermagem e médicos que atuam na Unidade de Emergência de um hospital geral.

\section{MATERI AL E MÉTODOS}

Pesquisa descritiva, de abordagem quantitativa, desenvolvida em uma Unidade de Emergência de um hospital geral da região noroeste do estado do Rio Grande do Sul, considerado referência em saúde. O referido hospital é filantrópico, atende pacientes de diferentes complexidades, com média de ocupação dos leitos de $74,55 \%$, permanência de 5,25 dias e taxa de mortalidade de $5,20 \%$. A equipe de profissionais totaliza cento e quarenta médicos (140) e profissionais especializados em diversas áreas.

A Unidade de Emergência, local da pesquisa, conta com 24 leitos de observação. A mesma possui uma equipe composta por 03 enfermeiras, 27 técnicos em enfermagem, 03 auxiliares de enfermagem e 08 médicos plantonistas.

Integraram a pesquisa todos os profissionais da saúde (41) que atuam na referida unidade, e que, voluntariamente, aceitaram participar da mesma. Importante ressaltar que dois deles, mesmo aceitando participar, não devolveram os instrumentos. Após várias tentativas, sem sucesso, optou-se por excluí-los da população pesquisada; uma terceira profissional estava em perícia, portanto, afastada da unidade, não sendo possível integrá-la à pesquisa, perfazendo um total de 38 profissionais.

No que tange aos aspectos éticos, foram cumpridos todos os preceitos que envolvem uma pesquisa com seres humanos ${ }^{(7)}$. $O$ projeto de 
pesquisa foi encaminhado e aprovado pelo Comitê de Ética em Pesquisa da UNIJUI, sob parecer $\mathrm{n}$ 은 094/2007.

A coleta de dados foi realizada de 02 a 31 de julho de 2007, sendo utilizados os seguintes instrumentos: Inventário de Burnout de Maslach-MBI, validado por Lautert ${ }^{(8)}$, composto de 52 (cinqüenta e duas) perguntas fechadas, com grau de intensidade/freqüência para a resposta, seguido de um instrumento contendo dados sociodemográficos, criado e testado pelas pesquisadoras.

O "Inventário de Burnout" vem acompanhado de uma escala de conversão, a qual permite classificar as respostas dos pesquisados em: Desgaste Emocional, Despersonalização, Incompetência e uma escala de conversão no Contexto de Trabalho. Na análise quantitativa das variáveis que caracterizam a Síndrome de Burnout, utilizou-se uma escala do tipo Likert, com valores entre 1 e 5 para as respostas dos profissionais, considerando 1(nunca), 2(algumas vezes ao ano), 3(algumas vezes ao mês), 4(algumas vezes na semana) e 5(diariamente). A partir desta pontuação foi possível calcular média, desvio padrão e coeficiente de variação. Os dados foram analisados com o auxílio do software estatístico SPSS e apresentados em tabelas.

\section{RESULTADOS E DISCUSSÃO}

No que tange as características sociodemográficas dos profissionais, a pesquisa revela similaridade entre os gêneros feminino $(57,9 \%)$ e masculino $(42,1 \%)$. É uma população jovem, possuindo em média, 37,11 anos de idade, com desvio padrão de 13,$16 ; 60,5 \%$ é casada, $34,2 \%$ são solteiros, 5,3\% separados e $70,3 \%$ possui filhos. Do total de profissionais que integraram a pesquisa, $70,3 \%$ possui ensino médio, $2,7 \%$ graduação e $27,0 \%$ pós-graduação lato-sensu. Quanto a atividade profissional, $64,9 \%$ são técnicos de enfermagem, $18,9 \%$ médicos, $8,1 \%$ enfermeiros e $8,1 \%$ auxiliares de enfermagem.

Nesse contexto, as mulheres, embora mais estressadas do que os homens, sabem lidar melhor com o estresse do que eles. I sto ocorre por questões culturais, associadas às exigências que lhes são impostas, tais como trabalhar fora e, ao mesmo tempo, assumir responsabilidades domésticas. As mulheres apresentam menos doenças causadas pelo estresse, pois conseguem verbalizar seus sentimentos e problemas vivenciados no dia-a-dia ${ }^{(9)}$.

Pesquisa $^{(4)}$ revela que os jovens apresentam maiores níveis de Burnout, devido ao entendimento irrealístico a respeito do que podem ou não fazer e, portanto, tornam-se freqüentes as frustrações profissionais. Principalmente os recém formados, necessitam aprender a lidar com as demandas do trabalho e, por este motivo, podem vir a desenvolver maiores níveis de Burnout, ou seja, toda situação nova desencadeia insegurança e constitui-se em um agente estressor capaz de contribuir para o surgimento da síndrome. Os mais velhos provavelmente são dotados de estratégias mais eficazes de enfrentamento, desenvolvidas ao longo dos anos, o que os tornam menos vulneráveis aos estressores, consequentemente, adquirindo maior domínio sobre sua prática e mais autoconfiança ${ }^{(10)}$.

Analisando as variáveis estado civil e filhos, a reciprocidade e a estabilidade no amor e no desejo, a satisfação emocional de ser pai ou mãe e a sensação de responsabilidade por um microgrupo, são possíveis razões para um menor índice de doenças mentais, dentre elas, a Síndrome de Burnout em casados. A qualidade do relacionamento é um fator que influencia, consideravelmente, no surgimento da referida síndrome. Estas colocações são corroboradas em outro estudo ${ }^{(4)}$ que afirma que sujeitos com filhos apresentam índices menores de exaustão emocional.

Analisando o tempo de atuação dos profissionais, 34,2\% atuam em média há 3,5 anos na profissão, $44,7 \%$ há 3,5 anos no referido hospital e $55,3 \%$ trabalham, em média, 3,5 anos na Unidade de Emergência. Destaca-se que a Síndrome de Burnout pode surgir como conseqüência de um desgaste crônico pelo tempo de atuação e, também, devido à inexperiência do indivíduo no desempenho das suas atividades. Quanto maior o tempo de serviço em uma determinada área, maior o nível de estresse, existindo, portanto, uma correlação significativamente elevada entre estresse e tempo de atuação na área(11).

$\mathrm{Na}$ seqüência, são apresentados, discutidos e analisados os dados referentes à utilização do Inventário de Burnout de Maslach (MBI). O mesmo desconsidera os elementos antecedentes e as conseqüências de seu processo. A seguir são apresentadas tabelas que elucidam a freqüência com que os profissionais sentem cada uma das afirmações presentes nas diversas variáveis do Inventário.

A Tabela 1, a seguir, elucida a freqüência com que os profissionais sentem cada uma das afirmações na dimensão Desgaste Emocional. Esta pode ser entendida como uma situação na qual os trabalhadores sentem que não podem se entregar mais. Envolve sentimento de esgotamento da energia dos recursos emocionais próprios, experiência de estar emocionalmente desgastado devido ao contato diário com pessoas com as quais necessitam se relacionar em função de seu trabalho(2). 
Tabela 1: Freqüência com que o profissional sente cada uma das afirmações na escala do Desgaste Emocional ( $\mathrm{MBI}$ - Unidade de Emergência de um Hospital Geral do Noroeste do Estado do Rio Grande do Sul/2007).

\begin{tabular}{|c|c|c|c|c|c|}
\hline AFI RMAÇÕES & N (\%) & AVA(\%) & AVM(\%) & AVS(\%) & $\mathbf{D}(\%)$ \\
\hline $\begin{array}{l}\text { Sinto-me emocionalmente decepcionado (a) com } \\
\text { meu trabalho }\end{array}$ & 36,8 & 42,1 & 10,5 & 5,3 & 5,3 \\
\hline $\begin{array}{l}\text { Quando termino minha jornada de trabalho sinto-me } \\
\text { esgotado(a) }\end{array}$ & 10,5 & 31,6 & 36,8 & 18,4 & 2,6 \\
\hline $\begin{array}{l}\text { Quando me levanto pela manhã me deparo com } \\
\text { outra jornada de trabalho, sinto-me fatigado (a) }\end{array}$ & 50,0 & 26,3 & 7,9 & 15,8 & - \\
\hline Sinto que trabalhar todo o dia com gente me cansa & 47,4 & 31,6 & 5,3 & 10,5 & 5,3 \\
\hline Sinto que meu trabalho está me desgastando & 39,5 & 39,5 & 7,9 & 7,9 & 5,3 \\
\hline Sinto-me frustrado (a) por meu trabalho & 57,9 & 28,9 & 7,9 & 2,6 & 2,6 \\
\hline Sinto que estou trabalhando demais* & 18,4 & 34,2 & 21,1 & 15,8 & 7,9 \\
\hline $\begin{array}{c}\text { Sinto que trabalhar em contato direto com as } \\
\text { pessoas me estressa }\end{array}$ & 39,5 & 26,3 & 18,4 & 13,2 & 2,6 \\
\hline $\begin{array}{l}\text { Sinto-me como se estivesse no limite de minhas } \\
\text { possibilidades }\end{array}$ & 44,7 & 36,8 & 10,5 & 5,3 & 2,6 \\
\hline $\begin{array}{ll}* \text { * Um profissional não respondeu } & \text { AVA: algumas vez } \\
\mathrm{N}: \text { nunca; } & \text { AVM: algumas ve }\end{array}$ & $\begin{array}{l}\text { ao ano; } \\
\text { ao mês; }\end{array}$ & & D: diariame & & \\
\hline
\end{tabular}

Ao analisar os dados contidos na Tabela 1 , constata-se que $21,1 \%$ dos pesquisados sentem-se emocionalmente decepcionados e desgastados com seu trabalho, o que implica em constante relação com o outro. Estes dados correspondem aos que apresentam estes sentimentos algumas vezes ao mês, na semana ou diariamente. A grande incidência de quadros de esgotamento, dentre eles o da Síndrome de Burnout, se dá em trabalhadores de instituições assistenciais, especialmente na área da saúde, por estarem permanentemente expostos aos problemas e às preocupações daqueles a quem atendem profissionalmente ${ }^{(10)}$.

Igualmente, verifica-se que $23,7 \%$ dos profissionais ao se depararem com uma nova jornada de trabalho sentem-se fadigados algumas vezes ao mês ou na semana. Paralelamente, o sentimento relacionado a "estar esgotado ao término do turno de trabalho" totaliza 57,8\%, um percentual elevado, que corresponde a algumas vezes ao mês, na semana ou diariamente. Este resultado merece atenção e ações do gestor da respectiva unidade, visando a redução desse sentimento e, consequentemente, a ocorrência da Síndrome de Burnout. Quando as pessoas sentem a exaustão, normalmente é de forma intensa, tanto emocional quanto psicologicamente. Elas se sentem exauridas, consumidas e incapazes de reagir por si só e se recuperarem. Quando levantam pela manhã, estão quase tão cansadas quanto ao deitar, desenergisadas para iniciar uma nova jornada de trabalho(5).

Outro dado que chama atenção é que do total de pesquisados, $34,2 \%$ referem que trabalhar diretamente com pessoas os estressa algumas vezes ao mês, na semana ou diariamente. O Burnout é "resultante da constante e repetitiva pressão emocional associada ao intenso envolvimento com pessoas por longos períodos de tempo"(12).
Ainda, 44,8\% dos profissionais referem sentir estar trabalhando demais, além dos seus limites, algumas vezes ao mês, na semana ou diariamente. Daí a necessidade de atuação do gestor da unidade pesquisada, no sentido de avaliar o quadro de pessoas, quantitativa e qualitativamente, prevenindo danos à saúde das mesmas e com repercussões na qualidade da assistência aos usuários.

O excesso de trabalho talvez seja a indicação mais precisa de desequilíbrio entre o trabalhador e a instituição na qual trabalha. O mesmo aumenta, concomitantemente, com o ritmo do trabalho, interferindo na qualidade da assistência, nas relações com colegas e contribuindo para o desgaste físico e emocional do trabalhador ${ }^{(5)}$.

A Tabela 2, na seqüência, refere-se à Dimensão Despersonalização, que analisa atitudes negativas, impessoais, céticas e insensíveis dos profissionais para com as pessoas, especialmente usuários. Tratar usuários, colegas e a organização como objeto, é uma característica da Despersonalização ${ }^{(13)}$. Contribuindo, ela emerge em resposta ao Desgaste Emocional e a Incompetência (baixa realização profissional), como uma estratégia de afrontamento ou defensiva ${ }^{(13)}$. 
Tabela 2: Freqüência com que o profissional sente cada uma das afirmações na escala da Despersonalização ( MBI - Unidade de Emergência de um Hospital Geral do Noroeste do Estado do Rio Grande do Sul/2007).

\begin{tabular}{|c|c|c|c|c|c|}
\hline AFI RMAÇÕES (\% ) & N (\%) & AVA(\%) & AVM(\% ) & AVS(\%) & $\mathrm{D}(\%)$ \\
\hline $\begin{array}{c}\text { Sinto que estou tratando alguns usuários de meu trabalho } \\
\text { como se fossem objetos impessoais }\end{array}$ & 68,4 & 18,4 & 2,6 & 10,5 & - \\
\hline $\begin{array}{l}\text { Sinto que me tornei mais duro (a) com as pessoas, desde } \\
\text { que eu comecei este trabalho }\end{array}$ & 44,7 & 31,6 & 7,9 & 13,2 & 2,6 \\
\hline $\begin{array}{l}\text { Preocupo-me com este trabalho que está endurecendo-me } \\
\text { emocionalmente }\end{array}$ & 50,0 & 28,9 & 5,3 & 10,5 & 25,3 \\
\hline $\begin{array}{l}\text { Sinto que realmente não me importa o que ocorra com as } \\
\text { pessoas as quais tenho que atender profissionalmente }\end{array}$ & 86,8 & 5,3 & 5,3 & - & 13,2 \\
\hline $\begin{array}{c}\text { Parece-me que os receptores de meu trabalho culpam-me } \\
\text { por alguns de seus problemas }\end{array}$ & 31,6 & 36,8 & 15,8 & 13,2 & 2,6 \\
\hline
\end{tabular}

Os profissionais da Unidade de Emergência pesquisada, no que tange a Despersonalização, apresentam escores relativamente baixos, $86,8 \%$ deles afirmam que nunca ou algumas vezes ao ano tratam os usuários como objetos impessoais. Este dado sugere que a maioria dos trabalhadores e usuários do serviço mantém uma relação empática, possibilitando a construção de vínculos e uma assistência humanizada.

Por outro lado, verifica-se que $23,7 \%$ deles referem sensação de endurecimento emocional devido ao trabalho e $41,1 \%$ preocupam-se com esta situação algumas vezes ao mês, na semana ou diariamente. Paralelo a isto, $18,5 \%$ garante não importar-se com sentimentos dos usuários do serviço, demonstrando apatia algumas vezes ao mês e ou diariamente. Nesta etapa ocorre um endurecimento afetivo por parte do trabalhador, prevalecendo o cinismo e a dissimulação afetiva. É comum a ansiedade, a redução de metas do trabalho e do comprometimento com os resultados, além da redução do idealismo e alienação ${ }^{(13)}$.

Considerando que se trata de seres humanos, estes percentuais apresentados são altos para Despersonalização, merecedores de atenção e de ações. Aliado a isso, a sensação de que os usuários dos serviços culpam os profissionais pelos seus problemas é motivo de estresse e frustração e permeia a rotina de $31,6 \%$ destes, algumas vezes ao mês, na semana ou diariamente. Esta situação induz o profissional a questionamentos sobre até que ponto o seu trabalho tem sido fator de realização e satisfação(12). A grande incidência de quadros de esgotamento, entre eles o da Síndrome de Burnout em trabalhadores de instituições assistenciais, nas áreas da saúde e da educação, ocorre por estarem permanentemente expostos aos problemas e às preocupações daqueles a quem atendem ${ }^{(10)}$.

A dimensão Incompetência, evidenciada a seguir, na Tabela 3, refere-se aos sentimentos e situações que caracterizam a realização profissional de cada sujeito, bem como o sentimento de competência/capacidade no trabalho interpessoal. Incompetência refere-se à percepção de deterioração da autocompetência e falta de satisfação com as realizações e os sucessos de si próprio no trabalho ${ }^{(14)}$. 
Tabela 3: Freqüência com que o profissional sente cada uma das afirmações na escala da Incompetência, escore reverso (MBI - Unidade de Emergência de um Hospital Geral do Noroeste do Estado do Rio Grande do Sul/2007).

\section{AFI RMAÇÕES (\%)}

Sinto que posso entender facilmente como as pessoas que

tenho que atender se sentem a respeito das coisas*

Sinto que trato com muita efetividade os problemas das pessoas que tenho que atender

Sinto que estou influenciado positivamente na vida das pessoas através de meu trabalho

Sinto-me muito vigoroso (a) em meu trabalho

Sinto que posso criar, com facilidade, um clima agradável com os usuários no meu trabalho

Sinto-me estimulado (a) depois de haver trabalhado diretamente com quem tenho que atender

Creio que consigo muitas coisas valiosas nesse trabalho que desempenho

No meu trabalho eu manejo com os problemas emocionais com muita calma

* Um profissional não respondeu AVA: algumas vezes ao ano;

$\mathrm{N}$ : nunca;

AVM: algumas vezes ao mês;
N (\%) AVA(\%) AVM(\%) AVS(\%) D(\%)

5,3

18,4

73,7

$\begin{array}{lllll}5,3 & 7,9 & 7,9 & 18,4 & 60,5\end{array}$

$\begin{array}{lllll}2,6 & 2,6 & 13,2 & 7,9 & 73,7\end{array}$

5,3

2,6

5,3

23,7

63,2

2,6

$-$

2,6

7,9

86,8

$\begin{array}{llll}- & 2,6 & 5,3 & 28,9\end{array}$

2,6

$-$

5,3

92,1

5,3

2,6

13,2

78,9
AVS: algumas vezes na semana;

D: diariamente
Analisando as afirmações na dimensão Incompetência, observa-se que os profissionais da Unidade de Emergência estão relativamente tranqüilos em relação a este sentimento, isto é, grande parte dos percentuais é satisfatória. É gratificante verificar que $92,1 \%$ deles entendem facilmente como os usuários se sentem a respeito das coisas, se vêem estimulados para a realização do seu trabalho e sabem manejar com os problemas emocionais, com calma, algumas vezes na semana ou diariamente. Constata-se ainda que $86,9 \%$ deles julgam-se vigorosos no trabalho, $97,4 \%$ conseguem criar um clima agradável com os usuários e 97,4\% acreditam adquirir muitas coisas valiosas no trabalho que desempenham. Pensa-se que estes aspectos interferem positivamente na qualidade da assistência prestada ao usuário.

Paralelo a isto, verifica-se a presença de percentuais não tão satisfatórios, ou seja, respectivamente, $18,4 \%$ e $21,1 \%$ do total de pesquisados nunca, algumas vezes ao ano ou ao mês sentem que influenciam positivamente na vida dos usuários por meio do trabalho que realizam e tratam efetivamente os problemas dos usuários do serviço. A dimensão Incompetência é caracterizada pelo sentimento de inadequação e fracasso, tanto no seu trabalho quanto fora dele ${ }^{(3)}$. O trabalhador torna-se insatisfeito e incompetente na sua atividade profissional. Com base nesses resultados, aliados as colocações dos autores, evidencia-se que a maioria dos pesquisados se sente motivada, estimulada, demonstrando em suas respostas que gostam do que fazem e, provavelmente, esses sentimentos repercutem positivamente no desempenho profissional.

A Síndrome de Burnout não é um problema do indivíduo, mas do ambiente social no qual desempenha suas atividades laborais. Tem-se conhecimento de que muitas transformações têm ocorrido no mundo do trabalho, como por exemplo, as referentes à tecnologia, gestão organizacional, transitoriedade do emprego, dentre outras. Neste cenário, constroem-se novas maneiras de organizar o trabalho e as relações dos indivíduos com o mesmo, incluindo cargos, ambigüidade de funções, exigências de qualidade na execução das tarefas, qualificação e competência do trabalhador.

Na seqüência, são apresentados os resultados da escala de conversão - Contexto de Trabalho, a qual integra as seguintes dimensões: ambigüidade de funções, estrutura organizacional, sobrecarga de trabalho quantitativa, qualitativa, desenvolvimento da carreira e relações interpessoais. Na Tabela 4, a seguir, são apresentados os dados referentes a escala da Ambigüidade de Funções. Esta surge a partir do momento em que o trabalhador não tem clareza quanto ao papel que desempenha. Quando isso ocorre, pode se constituir em fator estressor ${ }^{(1)}$. Os autores complementam, afirmando que quando o papel do trabalhador é claramente definido, tornamse satisfatórias as diversas situações que envolvem a sua atividade no ambiente de trabalho. 
Tabela 4: Freqüência com que o profissional sente cada uma das afirmações na escala da Ambigüidade de Funções* ( $\mathrm{MBI}$ - Unidade de Emergência de um Hospital Geral do Noroeste do Estado do Rio Grande do Sul/2007).

\begin{tabular}{|c|c|c|c|c|c|}
\hline AFIRMAÇÕES (\%) & N (\%) & AVA(\%) & AVM(\% ) & AVS(\%) & $\mathrm{D}(\%)$ \\
\hline $\begin{array}{c}\text { Os deveres e os objetivos de meu trabalho são claros } \\
\text { para mim. }\end{array}$ & - & - & - & - & 100,0 \\
\hline $\begin{array}{l}\text { Possuo clareza a quem devo informar e quem deve } \\
\text { informar-me. }\end{array}$ & - & 2,6 & 2,6 & 5,3 & 89,5 \\
\hline $\begin{array}{c}\text { Eu tenho autoridade para levar a cabo minhas } \\
\text { responsabilidades no trabalho. }\end{array}$ & 10,5 & - & 2,6 & 18,4 & 68,4 \\
\hline $\begin{array}{c}\text { Eu entendo perfeitamente o que é esperado de mim } \\
\text { nesta instituição }\end{array}$ & 2,6 & - & 5,3 & - & 92,1 \\
\hline $\begin{array}{l}\text { Eu entendo a parte que meu trabalho representa no } \\
\text { encontro conjunto dos objetivos organizacionais. }\end{array}$ & 2,6 & - & 13,2 & 5,3 & 78,9 \\
\hline $\begin{array}{cc}\text { Escore reverso } & \text { AVA: algumas vezes } \\
\text { nunca; } & \text { AVM: algumas vezes }\end{array}$ & $\begin{array}{l}\text { ano; } \\
\text { mês; }\end{array}$ & & ariamente & & \\
\hline
\end{tabular}

Em relação aos dados da Tabela 4, constata-se que todos os profissionais possuem clareza dos deveres e objetivos do trabalho diariamente. Por conseguinte, $94,8 \%$ deles possuem clareza a quem devem informar e quem deve informá-los diariamente ou algumas vezes na semana, 92,1\% entendem perfeitamente 0 que a instituição espera deles diariamente.

Um percentual de $13,1 \%$ dos pesquisados afirma nunca ou algumas vezes ao mês possuir autoridade para realizar aquilo que é inerente às suas responsabilidades no ambiente de trabalho. Nesse contexto, os trabalhadores entram nas organizações com expectativas do que poderão realizar profissionalmente, o que a organização poderá oferecer-lhes o como recompensa e para facilitar seu trabalho. Com o passar do tempo estas expectativas são contrastadas com a realidade do dia-a-dia e tornam-se fatores potenciais para o desenvolvimento de Burnout ${ }^{(15)}$.

Verifica-se também que $13,2 \%$ dos profissionais algumas vezes ao mês têm consciência do significado do seu trabalho para a instituição e 2,6\% nunca. 0 sentimento de incerteza pode ser considerado um poderoso fator de estresse, uma vez que se apresenta ligado diretamente ao trabalho ${ }^{(1)}$. Contudo, é comum os trabalhadores apresentarem insegurança em relação à manutenção do emprego, do salário, sentimentos que ameaçam o que conseguiram com esforço, dedicação e, muitas vezes, sofrimento.

Na seqüência, é apresentada a Tabela 5 , que se refere à Estrutura Organizacional. Na atualidade, o trabalho representa para as pessoas um dos aspectos mais relevantes, para o qual dedicam boa parte de sua existência. Desta forma, o aparecimento de doenças pode estar relacionado aos impactos da organização do trabalho sobre a saúde, o bem-estar físico, mental e social dos trabalhadores. Os autores $^{(16)}$ afirmam que "o conceito de saúde organizacional está diretamente associado ao equilíbrio entre a estrutura, o funcionamento organizacional e o bem-estar individual".

Tabela 5: Freqüência com que o profissional sente cada uma das afirmações na escala da Estrutura Organizacional ( $\mathrm{MBI}$ - Unidade de Emergência de um Hospital Geral do Noroeste do Estado do Rio Grande do Sul/2007).

\begin{tabular}{|c|c|c|c|c|c|}
\hline AFI RMAÇÕES (\%) & N (\%) & AVA(\%) & AVM(\%) & AVS(\%) & $\mathbf{D}(\%)$ \\
\hline A estrutura formal da instituição tem muitos trâmites. & 7,9 & 7,9 & 21,1 & 21,1 & 42,1 \\
\hline $\begin{array}{l}\text { Eu estou no meio, entre as pressões de meus supervisores e } \\
\text { as de meus subordinados. }\end{array}$ & 26,3 & 21,1 & 15,8 & 15,8 & 21,1 \\
\hline $\begin{array}{l}\text { A corrente (cadeia) normal de comando não é observada, no } \\
\text { local onde trabalho.** }\end{array}$ & 26,3 & 18,4 & 15,8 & 15,8 & 18,4 \\
\hline $\begin{array}{l}\text { Meu grupo de trabalho não tem status ou prestigio na } \\
\text { organização.** }\end{array}$ & 34,2 & 18,4 & 13,2 & 13,2 & 15,8 \\
\hline Eu recebo solicitações conflitantes de duas ou mais pessoas. & 15,8 & 34,2 & 18,4 & 21,1 & 10,5 \\
\hline
\end{tabular}

Analisando a Tabela 5, 84,3\% dos profissionais percebem muitos trâmites na estrutura formal da instituição diariamente, algumas vezes na semana ou no mês. Este dado pode estar relacionado à burocracia da instituição que por vezes influencia no desenvolvimento das atividades dos profissionais, podendo contribuir para o estresse e o desgaste físico e emocional.

Do total de pesquisados, 36,9\% referem estar entre as pressões de seus supervisores e/ou subordinados diariamente ou algumas vezes na semana, enquanto que $47,4 \%$ deles relatam que esta 
situação ocorre algumas vezes ao ano ou nunca. No que se refere à corrente normal de comando no local de trabalho, esta é observada apenas por $26,3 \%$ dos profissionais, os demais não (algumas vezes no ano, no mês, na semana ou diariamente). Neste contexto, o conflito entre as metas e estrutura das empresas com as necessidades de autonomia, realização e de identidade, são estressores importantes, uma vez que a auto-estima fica diminuída, o trabalho é percebido como inútil e sem valor, seu esforço não é reconhecido socialmente, não havendo reforço de sua identidade por meio da práxis profissional ${ }^{(1)}$.

Ainda em relação aos dados da Tabela 5, verifica-se que $34,2 \%$ dos profissionais referem que sua equipe é prestigiada na organização, possui status, porém $60,6 \%$ deles afirmam que seu grupo de trabalho não possui prestígio/ status algum, variando a freqüência de respostas para algumas vezes ao ano, ao mês, na semana e diariamente. Destaca-se um percentual reduzido(15,8\%) de profissionais que nunca receberam solicitações conflitantes de duas ou mais pessoas em seu trabalho, sendo que o restante experimenta esta situação em uma freqüência variável (anual, mensal, semanal ou diariamente). Resultados de uma pesquisa com 37 profissionais de enfermagem que atuam em uma Unidade de Pronto Atendimento de um Centro de Saúde Escola mostram que as principais fontes de estresse estão relacionadas ao funcionamento organizacional, relacionamento interpessoal e sobrecarga de trabalho(17).

A partir da análise da Tabela 5, observa-se a importância de a equipe que atua na Unidade de Emergência reconhecer que existem dificuldades e que estas interferem negativamente no cotidiano do trabalho e, a partir disso, desenvolver ações que transformem estas condições. Isto só é possível se ocorrerem mudanças inclusive de concepções, valores e conceitos, resgatando o valor humano e, dessa forma, mantendo um bom padrão de qualidade de vida no trabalho.

A seguir, é apresentada a análise da variável Sobrecarga de Trabalho. Para favorecer a interpretação dos dados, esta foi subdividida em quantitativa (Tabela 6) e qualitativa (Tabela 7). A sobrecarga de papéis, qualitativa ou quantitativa se constitui em uma das principais causas de estresse; qualitativa, quando a pessoa não possui habilidades para desempenhar tal função e quantitativa quando se tem mais trabalho do que se pode realizar.

Tabela 6: Freqüência com que o profissional sente cada uma das afirmações na escala da Sobrecarga de Trabalho Quantitativa (MBI - Unidade de Emergência de um Hospital Geral do Noroeste do Estado do Rio Grande do Sul/2007).

\section{AFI RMAÇÕES (\%)}

N (\%) AVA(\%) AVM(\%) AVS(\%) D(\%)

Eu não tenho que levar trabalho para casa ao final do expediente e final de semana para colocá-los em dia.

Eu gasto algum tempo em reuniões importantes, que me gratificam em meu trabalho.

Eu sou responsável por um número manejável de tarefas e responsabilidades

Eu simplesmente tenho trabalho suficiente que posso executar, em um dia ordinário.

\begin{tabular}{ccccc}
81,6 & 5,3 & 2,6 & 5,3 & 5,3 \\
10,5 & 34,2 & 44,7 & 10,5 & - \\
- & - & 10,5 & 5,3 & 84,2 \\
7,9 & 5,3 & 10,5 & 21,1 & 55,3 \\
5,3 & 2,6 & 10,5 & 21,1 & 57,9 \\
\hline \multicolumn{5}{c}{ AVS: algumas vezes na semana; } \\
& D: diariamente
\end{tabular}

AVA: algumas vezes ao ano;

AVM: algumas vezes ao mês:
AVS: algumas vezes na semana

Tabela 7: Freqüência com que o profissional sente cada uma das afirmações na escala da Sobrecarga de Trabalho Qualitativa(MBI - Unidade de Emergência de um Hospital Geral do Noroeste do Estado do Rio Grande do Sul/2007).

\begin{tabular}{|c|c|c|c|c|c|}
\hline AFI RMAÇÕES (\%) & $\mathbf{N}(\%)$ & AVA(\%) & $\operatorname{AVM}(\%)$ & AVS(\%) & $D(\%)$ \\
\hline $\begin{array}{l}\text { As demandas de qualidade do trabalho são excessivas } \\
\text { para mim. }\end{array}$ & 42,1 & 26,3 & 10,5 & 15,8 & 5,3 \\
\hline $\begin{array}{l}\text { Minhas tarefas são, algumas vezes, muito difíceis e } \\
\text { complexas. }\end{array}$ & 15,8 & 31,6 & 21,1 & 26,3 & 5,3 \\
\hline $\begin{array}{l}\text { O pessoal da minha equipe está desmotivado e } \\
\text { produzindo um trabalho de baixa qualidade. }\end{array}$ & 15,8 & 39,5 & 18,4 & 13,2 & 13,2 \\
\hline $\begin{array}{c}\text { A organização espera mais de mim do que minha } \\
\text { habilidade e destreza proporcionam-me }\end{array}$ & 31,6 & 26,3 & 15,8 & 13,2 & 13,2 \\
\hline $\begin{array}{c}\text { Eu tenho insuficiente treinamento ou experiência para } \\
\text { cumprir algumas tarefas corretamente }\end{array}$ & 42,1 & 31,6 & 7,9 & 5,3 & 13,2 \\
\hline
\end{tabular}

$\mathrm{N}$ : nunca;

AVA: algumas vezes ao ano;
AVM: algumas vezes ao mês;

AVS: algumas vezes na semana;
D: diariamente 
No que se refere à Sobrecarga de Trabalho Quantitativa (Tabela 6), apenas $13,20 \%$ dos pesquisados afirmam não precisar levar trabalho para casa ao final do expediente, diariamente, algumas vezes na semana ou no mês. Os demais, $86,9 \%$, necessitam levar trabalho para casa diariamente. Todavia, ocorre uma contradição ao observar que $84,2 \%$ dos pesquisados referem que é possível manejar suas atividades diariamente. Igualmente, $55,3 \%$ afirmam ter tarefas suficientes para executar diariamente e $57,9 \%$ referem ter tempo para uma pausa em seu turno de trabalho diariamente e $21,1 \%$ a realizam algumas vezes na semana.

Ao se reportar a variável Sobrecarga de Trabalho Qualitativa (Tabela 7), 31,6\% dos pesquisados percebem que as demandas de qualidade do trabalho são exageradas, $52,7 \%$ referem que as tarefas são difíceis e complexas, $44,8 \%$ afirmam que sua equipe está desmotivada e produzindo um trabalho de baixa qualidade e $42,2 \%$ percebe que a organização exige mais deles em termos de habilidade e destreza do que podem realizar. Estas situações são percebidas pelos profissionais diariamente, algumas vezes na semana ou no mês.
Diante do complexo cenário que se apresenta a Unidade de Emergência pesquisada, felizmente $73,7 \%$ dos trabalhadores nunca ou algumas vezes ao ano se sentem insuficientemente qualificados para o cumprimento de suas tarefas. Considera-se, portanto, que eles estão satisfeitos com as capacitações/ qualificações que recebem pelo Programa de Educação Continuada existente na Organização, podendo atuar, inclusive, como um antídoto, protegendo a equipe estudada contra a Síndrome de Burnout. Este resultado igualmente mostra que o investimento que está sendo realizado pela referida instituição de saúde está produzindo resultados positivos.

Na Tabela 8, a seguir, evidencia-se a variável Desenvolvimento da Carreira. Nesta constata-se que $52,7 \%$ da população pesquisada vê possibilidades propícias de crescimento na Organização diariamente ou algumas vezes na semana, enquanto que, respectivamente, $47,4 \%$ e $65,8 \%$ deles refere nunca, algumas vezes ao ano ou no mês ter oportunidade de avançar na Organização e/ou atingir níveis mais altos. Neste sentido, a Síndrome de Burnout pode ser conseqüência da falta de oportunidade para o profissional crescer em sua carreira ${ }^{(5)}$.

Tabela 8: Freqüência com que o profissional sente cada uma das afirmações na escala do Desenvolvimento da Carreira (MBI - Unidade de Emergência de um Hospital Geral do Noroeste do Estado do Rio Grande do Sul/2007).

\begin{tabular}{|c|c|c|c|c|c|}
\hline AFI RMAÇÕES (\%) & $\mathbf{N}(\%)$ & AVA(\%) & AVM(\%) & AVS(\%) & $D(\%)$ \\
\hline Tenho oportunidades propícias para avançar na organização. & 21,1 & 23,7 & 2,6 & 5,3 & 47,4 \\
\hline $\begin{array}{l}\text { Se eu quiser adquirir níveis mais altos de desenvolvimento, } \\
\text { tenho possibilidades dentro dessa organização. }\end{array}$ & 18,4 & 42,1 & 5,3 & 5,3 & 26,3 \\
\hline $\begin{array}{c}\text { Não estou sacrificando meu progresso na carreira por estar } \\
\text { nesta instituição.* }\end{array}$ & 71,1 & 18,4 & 7,9 & - & - \\
\hline $\begin{array}{c}\text { Eu tenho oportunidades para crescer e obter novos } \\
\text { conhecimentos no meu trabalho. }\end{array}$ & 2,6 & 26,3 & 7,9 & 2,6 & 60,5 \\
\hline Sinto que estou progredindo em minha carreira. & - & 10,5 & 7,9 & 10,5 & 71,1 \\
\hline $\begin{array}{l}\text { AVA: algumas vezes ao ar } \\
\text { AVM: algumas vezes ao } \mathrm{m}\end{array}$ & & $\begin{array}{l}\text { AVS } \\
\text { D: } d\end{array}$ & nente & & \\
\hline
\end{tabular}

A grande maioria dos profissionais $(97,4 \%)$ afirma nunca, algumas vezes ao ano ou ao mês sacrificarem seu progresso na carreira por atuar na referida Unidade de Emergência. Este dado se contrapõe ao exposto anteriormente, logo, identificase que a dificuldade de desenvolvimento na carreira não está relacionada à organização em que atuam e sim a fatores intrínsecos do próprio profissional. Esta constatação pode ser confirmada pelo fato de que $60,5 \%$ deles referem ter oportunidade para crescer e obter novos conhecimentos em seu trabalho e $71,1 \%$ afirma progredir em sua carreira na instituição. O sucesso da organização está diretamente relacionado à sua capacidade de desenvolver pessoas e este desenvolvimento deve respeitar a individualidade de cada uma delas ${ }^{(9)}$.

O trabalhador é responsável pela gestão de seu desenvolvimento, de sua competitividade profissional, bem como de sua carreira. Ele necessita ter consciência de seu papel e cobrar de si a gestão de sua carreira, assim como exigir da organização condições objetivas para seu desenvolvimento profissional.

A seguir, na Tabela 9, é apresentada a última variável analisada no Contexto de Trabalho, a das Relações Interpessoais, a qual proporciona apoio ao trabalhador no sentido de conseguir lidar com situações que envolvem desgaste e estresse, inerentes ao trabalho. 
Tabela 9: Freqüência com que o profissional sente cada uma das afirmações na escala das Relações Interpessoais ( MBI - Unidade de Emergência de um Hospital Geral do Noroeste do Estado do Rio Grande do Sul/2007).

\begin{tabular}{|c|c|c|c|c|c|}
\hline AFI RMAÇÕES (\% ) & N (\%) & AVA(\%) & AVM(\%) & AVS(\%) & $D(\%)$ \\
\hline $\begin{array}{l}\text { Meus colegas de trabalho não possuem espírito de equipe e } \\
\text { atuam de forma individualista. }\end{array}$ & 18,4 & 18,4 & 26,3 & 34,2 & 2,6 \\
\hline $\begin{array}{c}\text { Existem conflitos entre a minha equipe de trabalho e as de } \\
\text { outras unidades do hospital. }\end{array}$ & 18,4 & 34,2 & 21,1 & 21,1 & 5,3 \\
\hline $\begin{array}{c}\text { Eu percebo falta de coleguismo entre os integrantes da } \\
\text { equipe }\end{array}$ & 13,2 & 26,3 & 13,2 & 26,3 & 21,1 \\
\hline $\begin{array}{l}\text { Faltam-me oportunidades para discutir meus sentimentos } \\
\text { sobre o trabalho. }\end{array}$ & 39,5 & 18,4 & 10,5 & 10,5 & 21,1 \\
\hline $\begin{array}{l}\text { Sinto dificuldades para realizar um trabalho interdisciplinar } \\
\text { com as demais equipes com as quais atuo. }\end{array}$ & 52,6 & 23,7 & 10,5 & 13,2 & - \\
\hline
\end{tabular}

$\mathrm{N}$ : nunca;

AVA: algumas vezes ao ano;

AVM: algumas vezes ao mês;

AVS: algumas vezes na semana;

D: diariamente

Da população pesquisada, $63,1 \%$ sentem que os colegas não possuem espírito de equipe, atuam de maneira individualista e $60,6 \%$ percebem a falta de coleguismo entre os integrantes da equipe diariamente, algumas vezes na semana ou no mês. Nas mesmas freqüências, aproximadamente $50 \%$ dos profissionais sentem falta de oportunidades para discutir sentimentos sobre o trabalho $(42,1 \%)$ e mencionam a existência de conflitos entre a equipe de trabalho e as de outras unidades do hospital $(47,5 \%)$. Estes dados são contraditórios, se considerado que $76,3 \%$ deles referem nunca ou algumas vezes ao ano sentir dificuldade para realizar trabalho interdisciplinar.

Nesta perspectiva, estudos posteriores sobre estes aspectos são relevantes, tendo em vista que situações como estas, quando mal resolvidas, paralisam os envolvidos e interferem na capacidade de funcionamento da organização. Neste contexto, as relações interpessoais entre as diferentes categorias profissionais estão intimamente ligadas à satisfação ou não do trabalhador no contexto laboral. Quando tais relações são de apoio, se constituem em um importante fator protetor contra o estresse ${ }^{(1)}$.

$\mathrm{Na}$ seqüência, é apresentada e discutida a análise quantitativa das variáveis que caracterizam a Síndrome de Burnout, utilizando-se uma escala do tipo Likert (considerando os escores expostos em materiais e métodos), por meio da estatística descritiva, calculando média, desvio padrão e coeficiente de variação do total de profissionais, bem como separadamente, da equipe de enfermagem e da equipe médica.

A avaliação da Síndrome de Burnout se dá de acordo com os escores de cada dimensão. Desta forma, altos escores de Desgaste Emocional e Despersonalização e baixos escores de Incompetência (escore reverso), são indicativos de Burnout. Destaca-se a importância de avaliar o inventário, considerando sua característica tridimensional, a fim de manter a sua perspectiva de síndrome ${ }^{(4)}$.

A Síndrome de Burnout pode ser observada em todas as profissões, principalmente nas que envolvem altos níveis de estresse, como as da área da saúde. Isso se deve às características inerentes à profissão, tais como o convívio com o outro, a interação emocional intensa e a indisponibilidade para atividades de lazer e férias, mas também devido às transformações do mundo do trabalho. Sabe-se que estas implicam também em mudanças nas relações sociais e de trabalho, incluindo o bem-estar físico e mental dos trabalhadores e dos grupos sociais que eles integram. Considerando o exposto, é possível que existam variáveis da síndrome em ambas as equipes, com intensidades diferentes, as quais podem ser verificadas na Tabela 10, analisada e discutida a seguir.

Tabela 10: Estatística descritiva dos escores** do Inventário de Burnout de Maslach - MBI - Unidade de Emergência de um Hospital Geral do Noroeste do Estado do Rio Grande do Sul - 2007.

\begin{tabular}{cccccccccc}
\hline $\begin{array}{c}\text { ESCALA DE CONVERSÃO } \\
\text { Equipe }\end{array}$ & \multicolumn{3}{c}{ MÉDI A } & \multicolumn{4}{c}{ DESVI O PADRÃO } & \multicolumn{3}{c}{ CV(\% ) } \\
Geral & Enf. & Med. & Geral & Enf. & Med. & Geral & Enf. & Med. \\
\hline Desgaste Emocional & 2,08 & 1,91 & 2,87 & 0,35 & 0,36 & 0,57 & 16,86 & 18,72 & 19,80 \\
Despersonalização & 1,78 & 1,60 & 2,60 & 0,37 & 0,36 & 0,75 & 20,65 & 22,20 & 28,92 \\
Incompetência* & 4,56 & 4,57 & 4,45 & 0,21 & 0,21 & 0,39 & 4,58 & 4,54 & 8,83 \\
\hline
\end{tabular}

*Escore reverso

**Escala do tipo Likert, com valores entre 1 e 5 para as respostas dos profissionais, considerando 1(nunca), 2(algumas vezes ao ano), 3(algumas vezes ao mês), 4(algumas vezes na semana) e 5(diariamente). 
Das três dimensões da Síndrome de Burnout, o Desgaste Emocional, a Despersonalização e a Incompetência nos profissionais pesquisados, verificaram-se escores reduzidos nas duas primeiras e elevado na Incompetência, sendo esta uma subescala inversa, avaliada de modo contrário. Nesta perspectiva, ao analisar as médias na Tabela 10, observa-se que nas duas primeiras categorias, os escores obtidos foram baixos, enquanto que na categoria Incompetência (escore reverso) eles apresentam valores mais elevados, demonstrando baixo nível de Burnout, tanto no total de pesquisados quanto nas duas equipes, separadamente. Em relação aos coeficientes de variação, os percentuais se mantiveram abaixo de $30 \%$, evidenciando homogeneidade das respostas dos profissionais. Quando analisada comparativamente, a Despersonalização obteve variabilidade mais acentuada em relação às demais, em ambas as análises.

$\mathrm{Na}$ análise comparativa das variáveis entre equipe médica e de enfermagem, as médias de Desgaste Emocional e Despersonalização apresentaram valores mais elevados na equipe médica e na Incompetência, apresentou similaridade nas duas categorias. A estafa profissional atinge um em cada dois médicos, sendo um terço deles afetado de forma importante e um décimo de forma severa, com características irreversíveis ${ }^{(18)}$. Os autores pontuam que $40 \%$ a $50 \%$ dos médicos que trabalham com medicina de emergência e infectologia são acometidos pela Síndrome de Burnout. Corroborando, já nos anos 80 , em conseqüência de doenças psiquiátricas, a taxa de suicídio era mais elevada nos médicos do que na população em geral. Atualmente os suicídios representam 38\% das mortes prematuras em médicos e quatro vezes superiores nas mulheres do que na população em geral. Os suicídios em médicas são superiores àqueles existentes em qualquer outro grupo profissional $^{(19)}$.

No que tange a enfermagem, desde o seu surgimento até os dias atuais, o enfermeiro tem buscado auto-realização, identidade profissional, visando reconhecimento. Nesta trajetória ele enfrenta dificuldades, as quais repercutem tanto no seu trabalho, quanto na sua vida pessoal.

$\mathrm{Na}$ análise das variáveis da Síndrome de Burnout relacionadas ao Contexto do Trabalho (Tabela 11), constata-se escores mais elevados nas variáveis Estrutura Organizacional, Sobrecarga de Trabalho Quantitativa, Desenvolvimento da Carreira e Relações Interpessoais, tanto para a equipe de enfermagem quanto para a médica, porém, a segunda categoria profissional obteve médias mais altas em relação à primeira. Este resultado permite identificar inadequações no contexto laboral da Unidade de Emergência, as quais podem contribuir para a geração e manutenção de níveis elevados de estresse, podendo evoluir para a Síndrome de Burnout.

Tabela 11: Estatística descritiva dos escores** do Inventário de Burnout de Maslach no Contexto de Trabalho (MBI - Unidade de Emergência de um Hospital Geral do Noroeste do Estado do Rio Grande do Sul/2007).

\begin{tabular}{cccccccccc}
\hline $\begin{array}{c}\text { Escala de conversão } \\
\text { Contexto de trabalho } \\
\text { Equipe }\end{array}$ & \multicolumn{3}{c}{ Média } & \multicolumn{4}{c}{ Desvio Padrão } & \multicolumn{3}{c}{ CV(\%) } \\
& Geral & Enf. & Med. & Geral & Enf. & Med. & Geral & Enf. & Med. \\
\hline Ambigüidade de Funções* & 4,71 & 4,71 & 4,69 & 0,25 & 0,31 & 0,21 & 5,36 & 6,47 & 4,52 \\
Estrutura Organizacional & 2,96 & 2,91 & 3,35 & 0,49 & 0,53 & 0,69 & 16,68 & 18,24 & 20,55 \\
$\quad \begin{array}{c}\text { Sobrecarga de Trabalho } \\
\quad \text { (quantitativo) }\end{array}$ & 3,43 & 3,42 & 3,43 & 1,37 & 1,50 & 0,81 & 39,86 & 43,82 & 23,57 \\
$\begin{array}{c}\text { Sobrecarga de Trabalho } \\
\quad \text { (qualitativo) }\end{array}$ & 2,45 & 2,45 & 2,51 & 0,28 & 0,28 & 0,64 & 11,38 & 11,47 & 25,60 \\
$\begin{array}{c}\text { Desenvolvimento da Carreira } \\
\text { Relações Interpessoais }\end{array}$ & $\mathbf{3 , 1 6}$ & $\mathbf{3 , 2 1}$ & $\mathbf{3 , 2 6}$ & 1,18 & 1,35 & 1,12 & 37,45 & 42,13 & 34,45 \\
\hline
\end{tabular}

*Escore reverso

**Escala do tipo Likert, com valores entre 1 e 5 para as respostas dos profissionais, considerando 1(nunca), 2(algumas vezes ao ano), 3(algumas vezes ao mês), 4(algumas vezes na semana) e 5(diariamente).

Os profissionais pesquisados afirmam ter progresso em sua carreira, porém, evidencia-se uma heterogeneidade acentuada nas respostas, confirmada pelo desvio-padrão e coeficiente de variação elevados, 1,18 e 37,45\%, respectivamente (Tabela 11). Quando observada a equipe de enfermagem, a variabilidade das respostas é ainda maior. Nesse sentido, destaca-se a importância de cada vez mais a organização investir no aperfeiçoamento dos seus colaboradores, visando valorizá-los como seres humanos.

Em suma, os resultados referentes a Ambigüidade de Funções, exceto os relacionados a consciência do significado do seu trabalho para a instituição, conforme mencionado no parágrafo anterior, são positivos, uma vez que na Tabela 11 evidencia-se uma média elevada $(4,71)$ para Ambigüidade de Funções, considerando que esta é 
uma subescala inversa. Igualmente verifica-se a homogeneidade das respostas, obtendo-se um coeficiente de variação baixo (5,36\%). Esta constatação também acontece nas duas equipes, quando analisadas separadamente.

Ao analisar a sobrecarga de trabalho quantitativa, explicitada na Tabela 11, verifica-se uma média para esta variável de 3,43, um desvio padrão de 1,37 e um elevado coeficiente de variação $(39,86 \%)$. Paralelo a isto, constata-se, por meio do desvio-padrão elevado e coeficiente de variação acima de $30 \%$, uma acentuada heterogeneidade nas respostas dos pesquisados, o que pode significar que alguns se sentem sobrecarregados enquanto os demais conseguem manejar tranqüilamente com as atividades em seu cotidiano no trabalho. Esses dados são preocupantes e merecedores de atenção do gestor da respectiva unidade, considerando-se que a variável sobrecarga tem destaque importante no diagnóstico de Burnout, bem como para entendimento deste fenômeno.

A variável Sobrecarga de Trabalho Qualitativa obteve pontuação relativamente baixa. Esta afirmação baseia-se nos dados da Tabela 11, na qual se evidencia uma média de 2,45 , o que pode significar que, apesar de alguns profissionais se sentirem sobrecarregados, outros desempenham suas atividades normalmente. Desta forma, constatase que, possivelmente, estes últimos estão utilizando estratégias de enfrentamento ao estresse mais adequadas, de forma a minimizar os estressores existentes ou a percepção desses é diferente dos demais, reforçando a influência da subjetividade nas respostas ao estresse e, consequentemente, ao Burnout.

Logo, constata-se escores mais elevados nas variáveis Estrutura Organizacional, Sobrecarga de Trabalho Quantitativa, Desenvolvimento da Carreira e Relações Interpessoais, tanto para a equipe de enfermagem quanto para a médica, porém, a segunda categoria profissional citada obteve médias mais altas em relação à primeira. Este resultado permite identificar inadequações existentes no Contexto Laboral da Unidade de Emergência, as quais podem contribuir para a geração e manutenção de níveis elevados de estresse, podendo evoluir para a Síndrome de Burnout.

\section{CONCLUSÕES}

O hospital em que o presente estudo foi realizado possui especificidades e, em se tratando especificamente da Unidade de Emergência, os níveis de estresse podem ser mais elevados, uma vez que dor, doença e morte integram o cotidiano destes profissionais.

O objetivo de identificar e comparar variáveis da Síndrome de Burnout nos profissionais da saúde que atuam em uma Unidade de Emergência de um
Hospital Geral do Noroeste do Estado do Rio Grande do Sul foi concretizado. O uso do Inventário de Burnout de Maslach-MBI permitiu avaliar de forma qualitativa e quantitativa (escala Likert) as variáveis que caracterizam a Síndrome de Burnout. Pode-se afirmar que os profissionais pesquisados vivenciam inúmeros estressores no trabalho, quando estes são analisados nas freqüências algumas vezes ao mês, na semana ou diariamente.

Quando verificadas as três dimensões da Síndrome de Burnout, conforme a escala Likert, o Desgaste Emocional e a Despersonalização apresentaram escores reduzidos (médias baixas) e a Incompetência, escore elevado (média alta), sendo esta uma escala reversa, demonstrando baixo nível de Burnout, tanto no total de pesquisados quanto nas duas equipes, separadamente. Também se observou que os coeficientes de variação se mantiveram abaixo de $30 \%$, evidenciando homogeneidade das respostas dos profissionais em todas as categorias.

$\mathrm{Na}$ Síndrome de Burnout no Contexto do trabalho, as dimensões Ambigüidade de Funções, Estrutura Organizacional, Sobrecarga de Trabalho Qualitativa e Relações Interpessoais, demonstraram, igualmente, médias baixas e homogeneidade nas respostas dos pesquisados $(\mathrm{CV}<30 \%)$, tanto no geral como em ambas as categorias. Nas dimensões Desenvolvimento da Carreira e Sobrecarga de Trabalho Quantitativa, as médias são mais elevadas e o coeficiente de variação é maior que $30 \%$, evidenciando heterogeneidade nas respostas, tanto no geral quanto nas duas categorias profissionais estudadas, com exceção da variabilidade apresentada na segunda dimensão(sobrecarga de trabalho) na equipe médica. Cabe ressaltar que nas dimensões Sobrecarga de Trabalho Quantitativa e Desenvolvimento da Carreira a heterogeneidade das respostas foi maior na equipe de enfermagem.

Finalizando, a tomada de atitudes em prol da saúde dos trabalhadores é vital, considerando que as transformações técnicas e organizacionais introduzidas nos processos de trabalho têm suscitado acentuado desgaste nos mesmos. Desta forma, conclui-se que, sob certas condições, o trabalho pode contribuir para o adoecimento. Entretanto, muitas situações de insatisfação profissional podem ser solucionadas por ações simples, ou seja, a equipe atua em um espaço comum, dedica-se a objetivos comuns, sendo assim, o processo de transformação necessita ocorrer coletivamente, buscando oportunidades de crescimento e satisfação para que esta equipe continue atuando com comprometimento, responsabilidade, consciência crítica e se mantenha saudável.

\section{REFERÊNCIAS}

1. França $A C L$, Rodrigues AL. Stress e Trabalho: Uma abordagem Psicossomática. São Paulo: Atlas; 2002. 
2. Martínez OF, Cabrera $\mathrm{CH}$, Tapia AM, Suárez SM, Garcia BGDR. Burnout among resident physicians who work duty shifts in the emergency department. Emergencias. 2007; 19: 116-21.

3. Feliciano KVO, Kovacs $\mathrm{MH}$, Sarinho SW. Sentimentos de profissionais dos serviços de prontosocorro pediátrico: reflexões sobre burnout. Rev. Bras. Saúde Mater. Infant. 2005; 5(3): 319-27.

4. Carlotto MS, Nakamura AP, Câmara SG. Síndrome de Burnout em estudantes universitários da área da saúde. Revista Psico. 2006; 37(1):57-62.

5. Maslach C, Leiter MP. The truth about Burnout: how organization cause, personal stress and what to do about it. San Francisco: Jossey-Bass; 1997.

6. Martini S, Arfken CL, Balon R. Comparison of Burnout Among Medical Residents Before and After the Implementation of Work Hours Limits. Acad Psychiatry 2006; 30(4): 352-5.

7. Ministério da Saúde; Conselho Nacional da Saúde. Resolução 196/96 - Normas regulamentadoras de pesquisa envolvendo os seres humanos. Brasília (Brasil): Ministérioi da Saúde; 1996.

8. Lautert L. O desgaste profissional do enfermeiro [thesis]. Salamanca: Universidade Pontífica de Salamanca; 1995.

9. Rossi A M. Estressado, eu? Porto Alegre: RBS produções; 2004.

10. Mallar SC, Capitão CG. Burnout e hardiness: um estudo de evidência de validade. Revista Psico. 2004; 9(1): 19-29.

11. Caregnato, RC. Estresse da equipe multiprofissional na sala de cirurgia: um estudo de caso [dissertation]. Porto Alegre: Escola de Enfermagem/UFRS; 2002.

12. Carlotto MS, Nakamura AP, Câmara SG. Síndrome de Burnout em estudantes universitários da área da saúde. Revista Psico. 2006;37(1):57-62.

13. Murofuse NT, Abranches SS, Napoleão AA. Reflexões sobre estresse e burnout e a relação com a enfermagem. Rev Latino-am Enfermagem. 2005; 13(2): 255-61.

14. Borges L O, Argolo JCT, Pereira ALS, Machado EAP,Silva WS. A síndrome de burnout e os valores organizacionais: um estudo comparativo em hospitais universitários. Psicol. Refl. Crít. 2002; 15(1): 189-200. 15. Tamayo MR, Tróccoli BT. Exaustão emocional: relações com a percepção de suporte organizacional e com as estratégias de coping no trabalho. Estud. psicol. (Natal). 2002; 7(1): 37-46.

16. Campos ICM, Costa FN. Cultura e saúde nas organizações. Estud. psicol. (Natal). 2007;24(2):279-

82.

17. Calderero ARL, Miasso Al, Corradi-Webster CM. Estresse e estratégias de enfrentamento em uma equipe de enfermagem de Pronto Atendimento. Rev. Eletr. Enf. [Internet]. 2008 [cited 2009 mar 21];10(1):51-62. Available from: http://www.fen. ufg. br/revista/v10/n1/pdf/v10n1a05. pdf.

18. Giglio AD, Tucunduva LTCM, Garcia AP, Prudente FVB, Centofanti G,Souza CM, et al. A síndrome da estafa profissional em médicos cancerologistas brasileiros. Rev. Ass. Méd. Bras. 2006; 52(2): 108-12. 19. Frasquilho MA. Medicina, médicos e pessoas: compreender o stress para prevenir o burnout. Acta Médica Portuguesa. 2005; 18:433-44.

Artigo recebido em 16.06.08.

Aprovado para publicação em 25.05.09. 